\title{
Effects of Temperature, Wetness Duration, and Moisture on the Conidial Germination, Infection, and Disease Incubation Period of Glomerella cingulata
}

Bing Wang, Bao-Hua Li, Xiang-Li Dong, Cai-Xia Wang, and Zhen-Fang Zhang, College of Crop Protection and Agronomy, Qingdao Agricultural University; Key Lab of Integrated Crop Pests Management of Shandong Province, Qingdao, Shandong 266109, P. R. China

\begin{abstract}
Wang, B., Li, B.-H., Dong, X.-L., Wang, C.-X., and Zhang, Z.-F. 2015. Effects of temperature, wetness duration, and moisture on the conidial germination, infection, and disease incubation period of Glomerella cingulate. Plant Dis. 99:249-256.

Glomerella leaf spot (GLS) caused by Glomerella cingulata is a newly emergent disease that results in severe defoliation and fruit spots. Currently, GLS is not effectively controlled in China due to a lack of understanding of its epidemiology. Therefore, the effects of temperature, wetness duration, and moisture on conidial germination, infection, and the disease incubation period of GLS were examined by inoculating $\mathrm{cv}$. Gala apple leaves with a conidial suspension and performing in vitro germination assays. Conidia could germinate and form appressoria at temperatures ranging from 5 to $35^{\circ} \mathrm{C}$, with an optimum temperature of $27.6^{\circ} \mathrm{C}$. The germination of conidia required free water or a nearly saturated relative humidity, with only a few conidia germinating and forming appressoria when the RH was less than $99 \%$. The conidial germination dynamics at 10,25 , and $30^{\circ} \mathrm{C}$ were well represented by three logistic models. The infection of cv. Gala apple leaves by conidia

ness duration required for infection by conidia at different temperatures was described using a polynomial equation, and the lowest minimum wetness duration was $2.76 \mathrm{~h}$, which occurred at $27.6^{\circ} \mathrm{C}$ according to the polynomial. Successful infection by conidia was represented by the number of lesions per leaf, which increased with extended wetness durations at the conidial infection stage for six tested temperatures, with the exception of $10^{\circ} \mathrm{C}$, when the minimum wetness durations were satisfied. The associations of successfully infected conidia with wetness duration at temperatures of $15,20,25$, and $30^{\circ} \mathrm{C}$ were described by four logistic models. Conidia infections developed into visible lesions at temperatures ranging from 15 to $30^{\circ} \mathrm{C}$, and the shortest incubation period of 2 days was observed at $25^{\circ} \mathrm{C}$. These data and models can be used to construct forecasting models and develop effective control systems for Glomerella leaf spot.
\end{abstract} occurred at temperatures ranging from 15 to $35^{\circ} \mathrm{C}$. The minimum wet-
Glomerella leaf spot (GLS) of apple (Malus $\times$ domestica Borkh.) is caused by Glomerella cingulata (Stoneman) Spauld. \& H. Schrenk and has become a widespread and major public concern in China (29). GLS was first reported in 1988 in Brazil (17) and is now widespread in countries with apple production areas (28). The disease was noticed in August 1998 in two orchards in eastern Tennessee in the United States (7). In China, GLS was first detected in August 2011 in Fei-xian, Jiangsu Province (29), and currently, the disease has spread to seven provinces, which include almost all of the apple production areas.

The GLS pathogen infects apple leaves and causes many small black lesions with indistinct edges at the start of infection. Under warm and humid conditions, the lesions can expand rapidly and result in defoliation after 5 to 7 days of development (17,27-29). Infections on the fruit result in a large number of small brown to black colored lesions with diameters between 1 and $5 \mathrm{~mm}$, and these lesions stop growing 5 to 7 days after infection. Gala, Golden Delicious, Qinguan (a cultivar bred in China), and several other apple cultivars are highly susceptible, and GLS has resulted in greater than $90 \%$ defoliation and diseased fruits in susceptible cultivars prior to harvest in the disease-stricken regions of China. However, the Fuji and Red Star cultivars are highly resistant to the disease.

Epidemics of GLS are mainly influenced by temperature and humidity and cause heavy losses in regions with humid subtropical climates, such as southern Brazil, southeastern United States, and eastern China (28). GLS often causes extensive defoliation in July and August in China, when the average monthly temperature

Corresponding author: B.-H. Li, E-mail: baohuali@qau.edu.cn

Accepted for publication 15 August 2014.

http://dx.doi.org/10.1094/PDIS-04-14-0361-RE

(C) 2015 The American Phytopathological Society ranges from 25 to $30^{\circ} \mathrm{C}$, and defoliation is especially common after a long period of rain. The spread of GLS is rapid and can lead to more than $90 \%$ defoliation within 1 to 2 months after primary infection. The diseased leaves from primary infections have been observed in June, whereas most of the leaves drop in mid-July to early August due to the rapid spread of the disease. Moreover, in August and September, G. cingulata can produce perithecia and ascospores in the leaf lesions, which can be dispersed over long distances and infect apple trees in orchards far from the source of infection.

To date, no approach has been able to effectively control GLS outbreaks. Traditional spraying systems do not prevent the defoliation of susceptible cultivars in China. Because the epidemiology of GLS is poorly understood and forecasting methods have not been produced, the extensive application of several fungicides, such as prochloraz, thiophanate-methyl, tebuconazole, and pyraclostrobin in numerous orchards has not effectively controlled the disease. The development of effective management systems to control the GLS epidemic is urgently required. An understanding of the epidemiology of the disease is an essential step for developing effective management systems and disease prediction models.

The germination and infection of spores are key steps in the epidemiology of this disease. Spores of pathogenic fungi are sensitive to temperature and moisture, and determining the effects of temperature, wetness duration, and moisture on the germination and infection of spores is required to understand the epidemiology of GLS and develop forecasting models based on weather conditions. In the mid-1920s, Keitt and Jones published studies focused on the temperature and minimum hours of wetness required for infection by ascospores of Venturia inaequalis $(13,15)$. Mills constructed a table based on these studies to describe the duration of leaf wetness required for light, moderate, and severe infection by ascospores of $V$. inaequalis and used this table to guide fungicide applications in scab management (24). The use of Mills' table led to great success in the management of apple scab, and this method has been used throughout the world $(5,6,11,12,26,30)$. Microcomputer-based 
instruments and computer programs were developed based on Mills' table to predict the infection periods and quantity of apple scab $(13,30)$. The concept of predicting infection periods and quantities of infected individuals based on the temperature and minimum duration of wetness required for infection by pathogens has been widely practiced in epidemiological studies and the management of plant diseases, such as pear scab, pear rust, and cucurbit downy mildew $(1,3,4,18-20,22,23,25)$.

GLS is an emerging disease of apple trees, and only a few studies have focused on the epidemiology of this disease. G. cingulata produces cylindrical conidia with rounded ends and morphological characteristics the same as those of Colletotrichum gloeosporioides $(8,9)$. Conidia are the primary infection source in the early stages of disease epidemics. Velho et al. (28) determined that GLS was favored by conditions of high humidity and temperatures between 23 and $28^{\circ} \mathrm{C}$. Luciano et al. (21) investigated the effect of wetness duration on the infection of apple leaves by the conidia of $G$. cingulata in a growth chamber and found that disease severity increased proportionally to increases in temperature from 14 to $28^{\circ} \mathrm{C}$. However, infection was completely inhibited at $34^{\circ} \mathrm{C}$. The duration of leaf wetness required for infection ranged from $2 \mathrm{~h}$ at $30^{\circ} \mathrm{C}$ to $32 \mathrm{~h}$ at $16^{\circ} \mathrm{C}(21)$.

In the present study, we conducted several experiments with $G$. cingulata conidia and detached cv. Gala shoots under controlled environments to determine the epidemiology of GLS, with an emphasis on the following: 1) the effects of temperature on conidia undergoing in vitro germination, conidial infection on leaves, and disease incubation period on leaves; 2) the moisture required for conidial germination and the effects of wetness duration on conidial infection; and 3) the dynamics of germination and infection by conidia. These data can be used to develop models to predict the infection periods and quantity of individuals infected by $G$. cingulata based on weather data.

\section{Materials and Methods}

Inoculum. Apple leaves of cv. Gala with fresh GLS lesions were sampled in September 2011 from an orchard located in Laixi, Shandong Province, China. The leaves were sanitized in $75 \%$ ethyl alcohol for $10 \mathrm{~s}$, washed with sterile distilled water, transferred to petri dishes, and then incubated at $25^{\circ} \mathrm{C}$ for 3 to 5 days to promote sporulation of the pathogen. Single conidial isolates were obtained by collecting and transferring single conidia to potato dextrose agar medium (PDA) according to the methods described by Dong (2). The pathogenicity of the isolates was tested by inoculating cv. Gala leaves with the conidial suspension and confirming that the infection was consistent with the pathogen on the sampled leaves. The isolates were stored in a refrigerator at $5^{\circ} \mathrm{C}$. One isolate was coded GLS010101 and grown in PDA medium before each inoculation.

To reproduce the conidia, mycelia were transferred to several petri dishes containing PDA medium and cultured for 5 days at $25^{\circ} \mathrm{C}$; the aerial mycelia were then scraped off and cultivated for another 5 days under UV light $(365 \mathrm{~nm})$. Newly formed conidia were collected using sterilized bamboo toothpicks and mixed with distilled water to prepare the conidial suspensions. The conidial suspensions used for the in vitro germination tests were adjusted to approximately $10^{6}$ conidia $\mathrm{ml}^{-1}$ using a hemocytometer, and the suspensions used for inoculation of the apple leaves were adjusted to approximately $10^{4}$ conidia $\mathrm{ml}^{-1}$.

Effects of temperature and $\mathrm{RH}$ on in vitro conidial germination. The effect of temperature on the conidial germination of $G$. cingulata was tested at eight different temperature levels $(5,10,15$, $20,25,30,35$, and $40^{\circ} \mathrm{C}$ ). For each level, four treatments at different relative humidities $(\mathrm{RH}=100,99,97$, and 95\%) and one treatment using free water were prepared. Thus, there were a total of 40 treatments of various temperature and moisture combinations. The temperature was controlled using eight incubators (BluePard MGC-250BP-2, Shanghai Bluepard Instruments Co. Ltd.), and the RH was achieved by amending the aqueous agar (Qing-dao Agar Powder Factory, China) with $0,0.3,0.9$, and $1.5 \mathrm{~mol} \mathrm{NaCl}$ in sealed dishes $(10,16)$.
Two petri dishes containing approximately $30 \mathrm{ml}$ of aqueous agar amended with the appropriate amount of $\mathrm{NaCl}$ (as described above) were prepared for each temperature $\times$ moisture combination. One slide was placed in the lid of each of the 80 petri dishes. Two 10- $\mu$ l drops of conidial suspension were separately placed on each of the two ends of the glass slide using a micropipette. After the two droplets were air dried at room temperature (ranging from 22 to $27^{\circ} \mathrm{C}$ ), the petri dish was immediately sealed with Parafilm (National Can, Chicago, USA). On average, it took approximately 10 to $20 \mathrm{~min}$ for the conidia suspension to dry. Glass slides for the free water treatments were placed in petri dishes containing $30 \mathrm{ml}$ of aqueous agar without $\mathrm{NaCl}$, and the droplets of conidial suspension were not allowed to air dry before the petri dishes were sealed with Parafilm. All the petri dishes were immediately placed into an incubator set to the appropriate temperature and allowed to incubate for $12 \mathrm{~h}$ prior to treatment.

After $12 \mathrm{~h}$ of incubation, all of the petri dishes were removed from the incubators, and a drop of cotton blue in lactophenol (lactic acid/phenol/glycerin/distilled water $=1: 1: 2: 1[\mathrm{v} / \mathrm{v} / \mathrm{v} / \mathrm{v}])$ was added to each spore suspension droplet to stop germination and preserve the conidia. The percentages of germinated conidia and conidia forming appressoria were estimated by randomly examining 50 conidia in the center of each inoculum point by microscopy (100× magnification; Leica DM500, Leica Microsystems, Wetzlar, Germany). The conidia were considered germinated when the germ tube was longer than half of the total length of the conidia and were considered to have formed appressoria when a distinct appressorium was formed on the tip of any of the germinated tubes. The lengths of the germinated conidia tubes in the free water treatments were measured by selecting the longest germination tube in each of five randomly selected visual fields at 100× magnification at each inoculum point. The experiment was repeated four times on different dates, and each incubator was randomly assigned to one of the tested temperatures in each replication.

Effect of temperature on the temporal dynamics of in vitro conidial germination. The effects of temperature on the temporal dynamics of the conidial germination of $G$. cingulata were examined at $5,10,15,20,25,30$, and $35^{\circ} \mathrm{C}$ by estimating the germination rate at different assessment times. For each temperature, 3 to 10 incubation treatments, ranging from 3 to $48 \mathrm{~h}$ with intervals of $1,2,3,4,10,12$, or $24 \mathrm{~h}$, were used (Fig. 1), for a total of 51 temperature $\times$ incubation period combinations.

One glass slide was placed in each lid of two petri dishes. Each dish contained approximately $30 \mathrm{ml}$ of aqueous agar to maintain $100 \% \mathrm{RH}$ inside the dish, and two dishes were used for each of the 51 combinations. Two 10- $\mu$ l drops of conidial suspension were separately placed on each of the two ends of the glass slide using micropipettes. The petri dishes were then sealed with Parafilm without air drying the droplets, and the dishes were immediately placed in the appropriate incubator.

At the end of each incubation period, a drop of cotton blue in lactophenol was added to each inoculum droplet to stop any further germination. The percentage of germinated conidia was estimated by randomly examining 50 conidia in each inoculum droplet under 100× magnification. The experiment was repeated four times on different dates.

Effects of temperature and wetness duration on infection. The effects of temperature on infection by $G$. cingulata conidia were examined at five temperature levels: 10, 15, 20, 25, 30, and $35^{\circ} \mathrm{C}$. Seven to 12 wetness duration treatments were arranged for each temperature, and there were 60 temperature $\times$ wetness duration combinations (Fig. 2). Two detached shoots of cv. Gala, each with four leaves, were inoculated for each combination.

In June and July, growing shoots with 6 to 10 leaves were cut from cv. Gala trees in a 4-year-old orchard to which fungicides had never been applied. Four of the youngest fully expanded, healthy leaves that were similar in size on each shoot were selected and surface-disinfected by soaking in a $0.08 \% \mathrm{NaOCl}$ solution for 2 to 3 min before rinsing with distilled water. Leaves that were not selected were cut off. After the leaves were air dried, two shoots 
for each combination were cultivated with their base inside a flask full of distilled water. All of the shoots were placed in the assigned incubators with $12 \mathrm{~h}$ of light $(12,000 \mathrm{~lx})$ at the proper temperatures for $12 \mathrm{~h}$ before inoculation. The shoots were then inoculated by spraying the conidial suspension on the leaves using a hand sprayer until the suspension flowed down from the leaves; the leaves were then separately covered with polythene bags to maintain the humidity and subsequently placed back into the incubators. All of the shoots were inoculated within 20 min of the conidia being placed into the water, which was also used as the start time of the wetness duration.

At the end of each wetness duration, the covered bags of two shoots were removed, and the shoots remained in the incubator to air dry for approximately 10 to $20 \mathrm{~min}$. All of the inoculated shoots were transferred to large chambers (MGC-800B, Shanghai Bluepard Instruments Co. Ltd.) maintained at $25^{\circ} \mathrm{C}$, with $75 \% \mathrm{RH}$ and $12 \mathrm{~h}$ of light $(20,000 \mathrm{~lx})$, for $48 \mathrm{~h}$ after inoculation. The shoots were kept in these chambers for an additional 7 days.

The lesions on each leaf were visually examined, and the number was recorded on the third, fifth, and eighth days after inoculation. Because the lesions could coalesce during growth, the highest number of lesions on each leaf among the three assessments was used as the final lesion number, and this number represented the proportion of successfully infected conidia. The experiments were repeated three times at $10^{\circ} \mathrm{C}$ and six times at the other temperatures.

The shortest wetness duration that induced disease in $5 \%$ of leaves (each diseased leaf had at least three lesions) was defined as
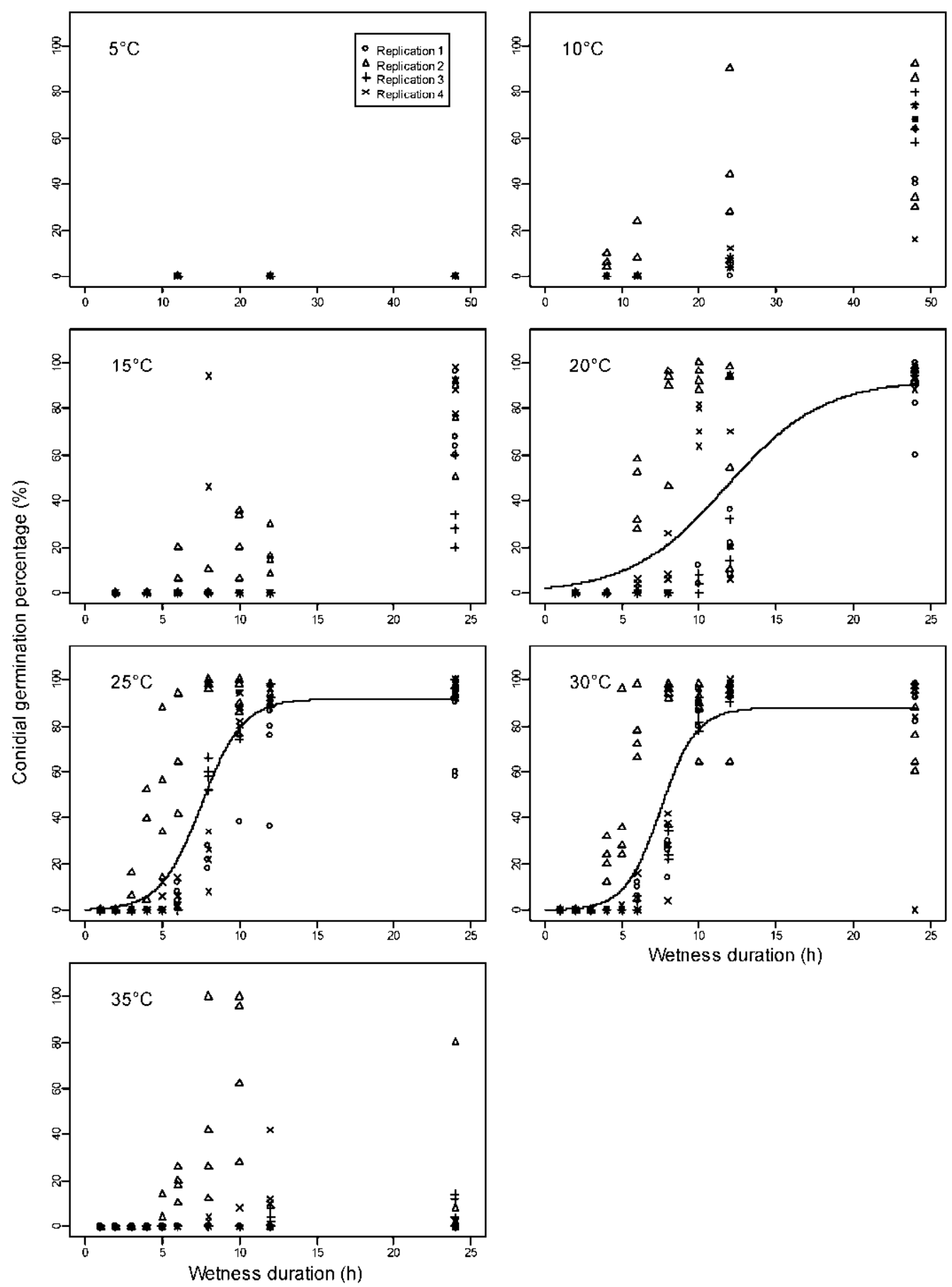

Fig. 1. Percentage of Glomerella cingulata conidia germinated in vitro after incubation in free water at seven tested temperatures for different periods of time. The symbols represent the observed values in four replications, and the solid lines are the curves of the fitted logistic models; their parameter values are listed in Table 3. 
the minimum wetness duration required for successful infection by conidia of G. cingulata (IMWD) in this study. At each temperature, the shortest wetness duration that induced more than three lesions (the maximum number was approximately 300 lesions per leaf) on at least two leaves (24 leaves in total) among the six repetitions was considered as the IMWD at that temperature.

Effect of temperature on incubation period. The effects of temperature on the GLS incubation period were tested at six temperatures: $10,15,20,25,30$, and $35^{\circ} \mathrm{C}$. The experiment was conducted in July, and two growing cv. Gala apple shoots, each with three young, fully expanded, healthy leaves, were detached and inoculated for each temperature treatment. All of the shoots were moved into large chambers kept at $25^{\circ} \mathrm{C}$, and high humidity was maintained by covering the shoots with polythene bags after inoculation. After $24 \mathrm{~h}$, the shoots were moved into six incubators that had been set to the appropriate temperatures 12 hours prior; the plants were kept under a 12-h light cycle $(12,000 \mathrm{~lx})$. The number of lesions on each leaf was assessed visually every day beginning on the third day after inoculation until the tenth day. The experiment was repeated three times on different dates.

Data analysis. ANOVA analysis was conducted using generalized linear models (GLM) to assess the effects of temperature and $\mathrm{RH}$ on conidial germination, appressorium formation, and germ tube growth. Replications were treated as block factors, temperature was treated as a whole plot factor, and $\mathrm{RH}$ was treated as a sub-plot factor in ANOVA. The percentage data at each of the observed points, which were assumed to follow a binomial distribution in the GLM, and the germ tube lengths of each conidium, which were assumed to follow a Gaussian distribution in the GLM, were applied in the data analysis and used to calculate means and standard deviations. Regression analysis was used to fit the means of conidial germination percentages obtained in four replications in the free water treatment and the IMWD to temperature. In the regression analysis, temperature $\left(T\right.$ in $\left.{ }^{\circ} \mathrm{C}\right)$ was considered the independent variable and was divided by 10 to avoid small values of estimated parameters. A logistic model was used to describe the conidial germination dynamics and infection dynamics:

$$
p=K /\{1+\exp [-\beta(t-M)]\}
$$

where $p$ is the proportion of geminated conidia or the lesion number per leaf and $t$ is time in hours. The observed data were used to estimate the parameters $K, M$, and $\beta: K$ is the maximum of $p ; M$ is the length of elapsed time until $p=K / 2$, and $\beta$ is the rate of germination or infection.

\section{Results}

Effects of temperature and RH on in vitro conidial germination. The ANOVA results showed that temperature, humidity, and the interaction of temperature with humidity had significant effects on in vitro germination and appressorium formation of $G$. cingulata conidia $(P<0.01)$. The variations in conidial germination and appressorium formation caused by $\mathrm{RH}$ accounted for 43.3 and
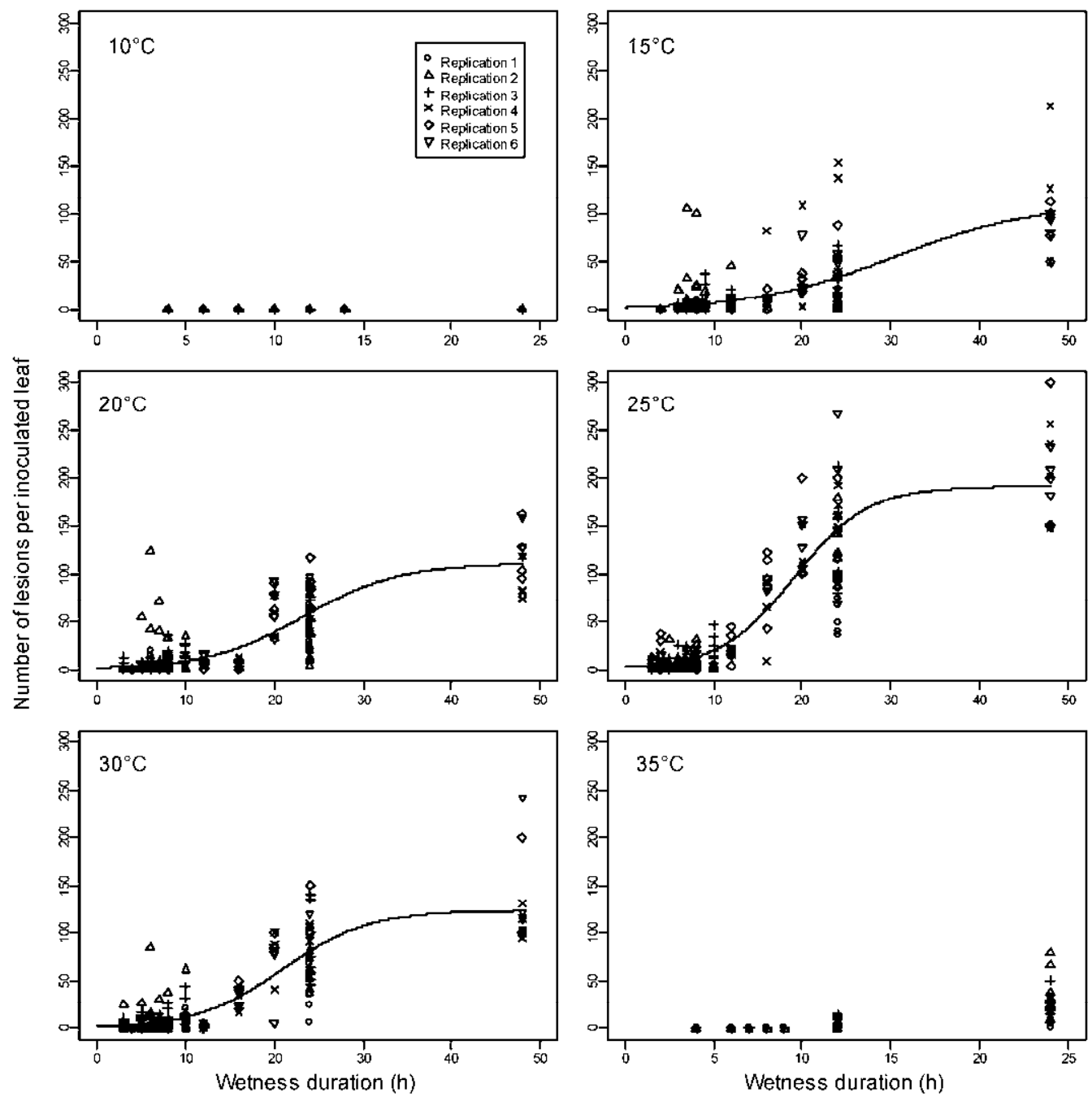

Fig. 2. Number of Glomerella leaf spots developed on each cv. Gala (Malus $\times$ domestica) apple leaf. The leaves were grown on detached shoots, which were water cultured and inoculated with a conidial suspension containing $10^{4}$ Glomerella cingulata conidia per ml; the wetness was maintained for different durations after inoculation at six temperatures. The symbols represent the observed values of the six replications, and the solid lines represent the curves of the fitted logistic models; their parameter values are listed in Table 4. 
$49.8 \%$ of the total variation according to the GLM model, whereas the variations caused by temperature accounted for 23.7 and $29.1 \%$ of the total variation, and the interaction of temperature with RH accounted for 4.6 and $5.13 \%$ of the total variation.

Conidial germination and appressorium formation of G. cingulata required free water or a high RH. In the free water treatment, $53.5 \%$ of the conidia at eight tested temperatures germinated (Table 1 ) and $25.1 \%$ of the conidia formed appressoria (Table 2); this number was significantly higher than that in the $100 \% \mathrm{RH}$ treatment $(P<0.01)$. The percentages of conidial germination and appressorium formation at $95 \% \mathrm{RH}$ were 3.6 and $0.0 \%$, respectively, which were significantly lower than the other moisture treatments $(P<0.01)$.

Temperature had a significant impact on conidial germination, appressoria formation, and germ tube growth (Tables 1 and 2, Fig. $3)$. In the free water treatment, the percentages of germinated conidia $(\mathrm{C} G P)$ at the examined temperatures $(T)$ were well-fitted $(P<$ $0.001)$ by a polynomial equation:

$$
\begin{gathered}
C G P=-(6.694 \pm 7.690)+(40.511 \pm 4.144) T^{2} \\
-(9.781 \pm 1.017) T^{3} \mathrm{R}-\text { square }=0.950
\end{gathered}
$$

The optimum temperature for conidia germination was $27.6^{\circ} \mathrm{C}$ according to the equation (Fig. 4).

The effect of temperature on the temporal dynamics of conidial germination. Germinated conidia were not detected at the $5^{\circ} \mathrm{C}$ treatment. The earliest times at which germinated conidia were observed were $8,6,6,3,4$, and $5 \mathrm{~h}$ for the samples incubated at 10 , $15,20,25,30$, and $35^{\circ} \mathrm{C}$, respectively. The percentages of germinated conidia increased as the wetness periods increased (Fig. 1). The conidial germination process at temperatures of 20,25, and $30^{\circ} \mathrm{C}$ was well-fitted $(P<0.05)$ by three logistic models (Eq. 1$)$. The three models accounted for $56.4,78.8$, and $75.3 \%$ of the total variance (Table 3). According to the models, the maximum germination percentages $(K)$ at 20,25 , and $30^{\circ} \mathrm{C}$ were $92.30,91.70$, and $87.81 \%$, respectively, and the incubation times required for $K / 2$ conidia germination were $11.77,7.56$, and $7.52 \mathrm{~h}$ (Table 3 ).

Effect of temperature on temporal dynamics of conidial infection. Lesions were not observed on the leaves inoculated at $10^{\circ} \mathrm{C}$, and the maximum number of lesions was observed on the

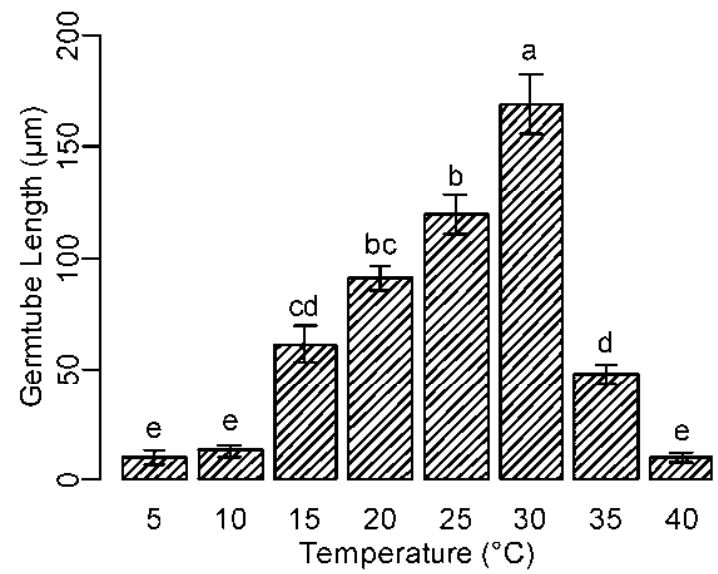

Fig. 3. Effects of temperature on the growth of Glomerella cingulata germination tubes. The average lengths of the germination tubes and the corresponding standard error (calculated from the observed data) at each temperature in the free water treatment (based on 40 conidia) is shown as a bar with an error bar. Different letters indicate that the germination tube lengths were significantly different $(P<$ 0.01 ) according to multiple comparisons of predicted values from the generalized linear model.

Table 1. Average percentages of in vitro conidial germination of Glomerella cingulata (based on 800 conidia) and the corresponding standard deviations at

\begin{tabular}{|c|c|c|c|c|c|c|}
\hline \multirow[b]{2}{*}{ Temperature $\left({ }^{\circ} \mathbf{C}\right)$} & \multirow[b]{2}{*}{ Free water } & \multicolumn{4}{|c|}{ Relative humidity $(\%)^{x}$} & \multirow[b]{2}{*}{ Mean } \\
\hline & & 100 & 99 & 97 & 95 & \\
\hline 5 & $8.5 \pm 15.5^{y}$ & $6.3 \pm 14.4$ & $2.6 \pm 4.4$ & $3.8 \pm 6.1$ & $4.1 \pm 9.1$ & $5.1 \pm 10.9 \mathrm{~d}$ \\
\hline 10 & $7.5 \pm 12.5$ & $1.4 \pm 2.4$ & $3.3 \pm 7.0$ & $1.1 \pm 2.2$ & $1.5 \pm 2.8$ & $3.0 \pm 7.0 \mathrm{e}$ \\
\hline 15 & $63.4 \pm 24.4$ & $21.8 \pm 38.8$ & $11.5 \pm 20.2$ & $4.9 \pm 11.3$ & $1.1 \pm 2.6$ & $20.5 \pm 31.9 c$ \\
\hline 20 & $79.0 \pm 13.5$ & $14.5 \pm 14.9$ & $10.5 \pm 13.9$ & $10.0 \pm 16.7$ & $1.0 \pm 1.8$ & $23.0 \pm 31.3 \mathrm{c}$ \\
\hline 25 & $90.8 \pm 10.5$ & $33.3 \pm 32.5$ & $31.8 \pm 23.9$ & $10.4 \pm 16.4$ & $6.8 \pm 17.3$ & $34.6 \pm 36.8 \mathrm{a}$ \\
\hline 30 & $92.0 \pm 9.6$ & $42.8 \pm 35.3$ & $31.8 \pm 31.9$ & $13.9 \pm 21.2$ & $3.8 \pm 6.2$ & $36.8 \pm 38.7 \mathrm{a}$ \\
\hline 35 & $71.1 \pm 24.2$ & $30.1 \pm 29.2$ & $23.9 \pm 22.1$ & $17.6 \pm 20.8$ & $10.3 \pm 19.4$ & $30.6 \pm 31.3 b$ \\
\hline 40 & $15.6 \pm 24.4$ & $0.13 \pm 0.5$ & $0.5 \pm 1.2$ & $0.1 \pm 0.5$ & $0.4 \pm 1.1$ & $3.4 \pm 12.4 \mathrm{e}$ \\
\hline Mean & $53.5 \pm 38.7 \mathrm{~A}^{\mathrm{z}}$ & $18.8 \pm 28.7 \mathrm{~B}$ & $14.5 \pm 21.7 \mathrm{C}$ & $7.7 \pm 15.0 \mathrm{D}$ & $3.6 \pm 10.3 \mathrm{E}$ & $19.6 \pm 30.6$ \\
\hline
\end{tabular}
various combinations of temperature and relative humidity assessed $12 \mathrm{~h}$ after inoculation

${ }^{x}$ Relative humidity was controlled by adding $\mathrm{NaCl}$ to the aqueous agar inside the sealed agar plates.

y Means and standard deviations were calculated from the data obtained from four replications.

${ }^{z}$ Different letters indicate that the percentages were significantly different $(P<0.01)$ according to multiple comparisons of values predicted by the generalized linear model. Upper case letters are for RH and lower case letters are for temperature.

Table 2. Average percentages of Glomerella cingulata conidia forming appressoria in vitro (based on 800 conidia) and the corresponding standard deviations at various combinations of temperature and relative humidity assessed $12 \mathrm{~h}$ after inoculation

\begin{tabular}{lcccccc}
\hline & & \multicolumn{4}{c}{ Relative humidity $(\boldsymbol{\%})^{\mathbf{x}}$} \\
\cline { 3 - 5 } Temperature $\left({ }^{\circ} \mathbf{C}\right)$ & Free water & $\mathbf{1 0 0}$ & $\mathbf{9 9}$ & $\mathbf{9 7}$ & $\mathbf{9 5}$ & \multicolumn{1}{c}{ Mean } \\
\hline 5 & $0.5 \pm 1.6^{\mathrm{y}}$ & $0.0 \pm 0.0$ & $0.1 \pm 0.5$ & $0.0 \pm 0.0$ & $0.1 \pm 0.5$ & $0.2 \pm 0.8 \mathrm{~d}$ \\
10 & $0.4 \pm 1.1$ & $0.0 \pm 0.0$ & $0.0 \pm 0.0$ & $0.0 \pm 0.0$ & $0.0 \pm 0.0$ & $0.1 \pm 0.5 \mathrm{~d}$ \\
15 & $20.3 \pm 24.5$ & $11.9 \pm 22.5$ & $0.0 \pm 0.0$ & $0.0 \pm 0.0$ & $0.0 \pm 0.0$ & $6.4 \pm 16.7 \mathrm{c}$ \\
20 & $53.0 \pm 22.6$ & $0.3 \pm 1.0$ & $0.1 \pm 0.5$ & $0.8 \pm 2.5$ & $0.0 \pm 0.0$ & $10.8 \pm 23.4 \mathrm{~b}$ \\
25 & $72.0 \pm 14.7$ & $8.3 \pm 12.0$ & $1.3 \pm 2.5$ & $1.0 \pm 3.1$ & $0.0 \pm 0.0$ & $16.5 \pm 29.3 \mathrm{a}$ \\
30 & $53.4 \pm 29.4$ & $16.1 \pm 23.2$ & $5.6 \pm 9.9$ & $3.9 \pm 9.1$ & $0.0 \pm 0.0$ & $15.8 \pm 26.2 \mathrm{a}$ \\
35 & $0.9 \pm 1.3$ & $1.0 \pm 2.2$ & $0.1 \pm 0.5$ & $0.3 \pm 1.0$ & $0.0 \pm 0.0$ & $0.5 \pm 1.3 \mathrm{~d}$ \\
40 & $0.3 \pm 0.7$ & $0.0 \pm 0.0$ & $0.0 \pm 0.0$ & $0.0 \pm 0.0$ & $0.0 \pm 0.0$ & $0.1 \pm 0.3 \mathrm{~d}$ \\
Mean & $25.1 \pm 32.3 \mathrm{~A}^{\mathrm{z}}$ & $4.7 \pm 13.3 \mathrm{~B}$ & $0.9 \pm 4.0 \mathrm{C}$ & $0.7 \pm 3.7 \mathrm{C}$ & $0.0 \pm 0.2 \mathrm{DA}$ & $6.3 \pm 18.4$ \\
\hline
\end{tabular}

${ }^{\mathrm{x}}$ Relative humidity was controlled by adding $\mathrm{NaCl}$ to the aqueous agar inside the sealed agar plates.

${ }^{y}$ Means and standard deviations were calculated from the data obtained from four replications.

${ }^{\mathrm{z}}$ Different letters indicate that the percentages were significantly different $(P<0.01)$ according to multiple comparisons of values predicted by a generalized linear model. Upper case letters are for RH and lower case letters are for temperature. 
leaves inoculated at $25^{\circ} \mathrm{C}$. The IMWDs were $6,5,3,3$, and $12 \mathrm{~h}$ for the samples incubated at $15,20,25,30$, and $35^{\circ} \mathrm{C}$, respectively. The maximum number of lesions per inoculated leaf increased with increasing durations of wetness at the infection stage after the IMWDs were satisfied (Fig. 2). The lesion numbers per leaf inoculated at temperatures of $15,20,25$, and $30^{\circ} \mathrm{C}$ were well-expressed $(P<0.05)$ by the four logistic models (Eq. 1). According to the models, the maximum number of lesions per leaf inoculated at 15 , 20,25 , and $30^{\circ} \mathrm{C}$ were $110.12,110.94,191.74$, and 123.89 , respectively, and the wetness duration required for conidial infection resulting in $K / 2$ lesions per leaf was $30.34,23.42,19.07$, and 20.87 h (Table 4).

The IMWD (in hours) at each treated temperature $(T)$ can be well described $(P<0.01)$ using a polynomial equation:

$$
\begin{gathered}
I M W D=(6.8940 \pm 0.2112)-(0.1666 \pm 0.0082) T^{5} \\
+(0.0504 \pm 0.0023) T^{6} \mathrm{R}-\text { square }=0.998
\end{gathered}
$$

This equation accounted for $99.80 \%$ of the total variance (Fig. 5). According to Equation 3, the optimum temperature for conidia infection was $27.6^{\circ} \mathrm{C}$, which was equal to the optimum temperature of germination. The IMWD was $2.76 \mathrm{~h}$ at the optimum temperature.

Effect of temperature on incubation period. Lesions did not develop on the inoculated leaves that were incubated at 10 and $35^{\circ} \mathrm{C}$. More lesions were observed in the leaves incubated at 25 and $20^{\circ} \mathrm{C}$ (Fig. 6) compared with those of the other temperature

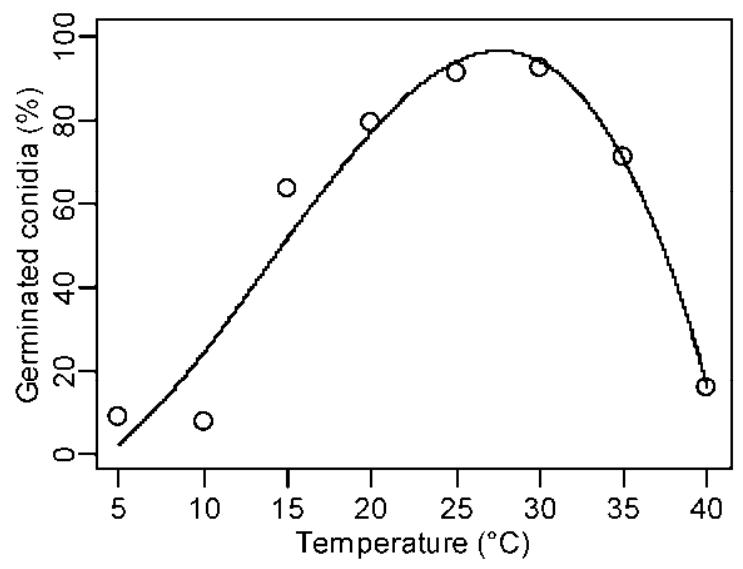

Fig. 4. Effects of temperature on conidial germination. Conidial germination percentage means in the free water treatment at each temperature were obtained from four replications and are shown as circles, and the fitted model curves (Eq. 2) are shown as a solid line. treatments. The first lesions to appear were observed on the third day after inoculation on leaves incubated at $25^{\circ} \mathrm{C}$. The minimum incubation periods, i.e., elapsed days from inoculation to the first lesions were observed, were 5, 4, 2, and 4 days at temperatures of $15,20,25$, and $30^{\circ} \mathrm{C}$, respectively. The lesion number increased within 5 days after inoculation. However, the lesion number was reduced with the expansion of lesions, and lesions coalesced after 5 days.

\section{Discussion}

The favorable temperature for $G$. cingulata conidial germination, conidial infection, and disease development was between 20 and $30^{\circ} \mathrm{C}$, with an optimum temperature of approximately $27.6^{\circ} \mathrm{C}$. This was consistent with experimental results from Brazil $(21,28)$. When the temperature was lower than $15^{\circ} \mathrm{C}$ or higher than $30^{\circ} \mathrm{C}$, only a few conidia were able to successfully infect the plant, and a small number of infections developed into visible lesions, although many conidia germinated and formed appressoria. Therefore, $15^{\circ} \mathrm{C}$ can be considered the lowest temperature that supports disease development, and $20^{\circ} \mathrm{C}$ is the baseline favorable temperature for disease epidemics. The overwintered pathogen would begin to grow and produce conidia when daily mean temperature was above $15^{\circ} \mathrm{C}$. When the daily mean temperature was above $20^{\circ} \mathrm{C}$ for 1 month (approximately 4 to 6 generations), the disease would reach epidemic status and result in the defoliation of the apple. Obviously, rain and moisture are important factors in disease epidemiology.

The conidial germination of $G$. cingulata required free water or a high moisture level. When the RH was lower than $99 \%$, only a few conidia germinated or formed appressoria, which is similar to what has been observed for many other fungal pathogens. Because the release and dispersion of $G$. cingulata conidia and ascospores require rain water, rain or irrigation by spraying may be the only trigger factor for pathogen infection in nature. The minimum wetness duration required for $G$. cingulata conidia infection was 2.76 $\mathrm{h}$ at an optimum temperature of $27.6^{\circ} \mathrm{C}$. This minimum wetness duration was slightly longer than that reported by Luciano et al. (21), which was only $2 \mathrm{~h}$ at $30^{\circ} \mathrm{C}$, and shorter than what is required for many other pathogens, such as $V$. inaequalis, $V$. nashicola, and Gymnosporangium asiaticum. However, the minimum wetness duration was similar to that required by $P$. cubensis $(2 \mathrm{~h})$. Thus, the infection rate was faster than the causal pathogens $V$. inaequalis, $V$. nashicola, and G. asiaticum and similar to P. cubensis, the causal agent of cucumber downy mildew. Rain that causes more than $3 \mathrm{~h}$ of leaf wetness could cause infection by $G$. cingulata conidia at the most favorable temperature, and this information can be used to estimate whether $G$. cingulata conidia might cause successful infections during rain.

Table 3. Parameter estimates of the logistic models in Figure 1 describing the temporal dynamics of Glomerella cingulata conidia in vitro germination and the corresponding R-square values at three temperatures.

\begin{tabular}{lcrcc}
\hline Temperature & $\boldsymbol{K}^{\mathbf{z}}$ & $\boldsymbol{M}^{\mathbf{z}}$ & $\boldsymbol{\beta}^{\mathbf{z}}$ & R-square \\
\hline $20^{\circ} \mathrm{C}$ & $92.30 \pm 7.453$ & $11.77 \pm 0.9488$ & $0.3206 \pm 0.0798$ & 0.564 \\
25 & $91.70 \pm 3.738$ & $7.56 \pm 0.2614$ & $0.7448 \pm 0.1012$ & 0.788 \\
30 & $87.81 \pm 3.816$ & $7.52 \pm 0.2635$ & $0.8646 \pm 0.1415$ & 0.753 \\
\hline
\end{tabular}

${ }^{\mathrm{z}}$ In the fitted logistic model $p=K /\{1+\exp [-\beta(t-M)]\}, P$ is the percentage of conidia germinated $(\%)$ at time $t, K$ is the maximum germination percentage (\%), $M$ is the length of time (h) elapsed until $P=K / 2$ and $\beta$ is the germination rate $\left(\% \mathrm{~h}^{-1}\right)$.

Table 4. Parameter estimates of the logistic models in Figure 2 describing the temporal dynamics of Glomerella cingulata conidial infection of cv. Gala (Malus $\times$ domestica) apple leaves and the corresponding R-square values at four temperatures.

\begin{tabular}{lllc}
\hline Temperature & \multicolumn{1}{c}{$\boldsymbol{K}^{\mathbf{z}}$} & $\boldsymbol{M}^{\mathbf{z}}$ & $\boldsymbol{\beta}^{\mathbf{z}}$ \\
\hline $15^{\circ} \mathrm{C}$ & $110.12 \pm 10.88$ & $30.34 \pm 2.75$ & $0.1286 \pm 0.02150$ \\
20 & $110.94 \pm 5.70$ & $23.42 \pm 0.80$ & $0.1857 \pm 0.01808$ \\
25 & $191.74 \pm 8.00$ & $19.07 \pm 0.59$ & $0.2402 \pm 0.01739$ \\
30 & $123.89 \pm 5.98$ & $20.87 \pm 0.70$ & $0.2059 \pm 0.01655$ \\
\hline
\end{tabular}

${ }^{\mathrm{z}}$ In the fitted logistic model $p=K /\{1+\exp [-\beta(t-M)]\}, P$ is the number of lesions on each leaf (lesions) inoculated with a conidial suspension containing $10^{4} \mathrm{G}$. cingulata conidia per $\mathrm{ml}$ and incubated under wet conditions for time $t, K$ is the maximum number of lesions per leaf (lesions), $M$ is the wetness duration (h) until $P=K / 2$ and $\beta$ is the infection rate (lesions $\mathrm{h}^{-1}$ ). 
Lesions on leaves of different ages did not show distinct differences in these experiments. In orchards that are seriously diseased, more than $95 \%$ of the leaves defoliate and the disease severity did not show an obvious difference on leaves of different ages. This result indicated that the susceptibility of all leaves of the susceptible to $G$. cingulata was not substantially different based on their age. The minimum wetness duration required for conidial infection was shorter than that required for conidial germination under the same temperature. This phenomenon indicates that there may be some instances that stimulate or promote germination and lead to faster conidia germination on apple leaves than in pure water.

The incubation periods of GLS were short, and the infection required 2 to 5 days to develop into visual lesions. This result sug-

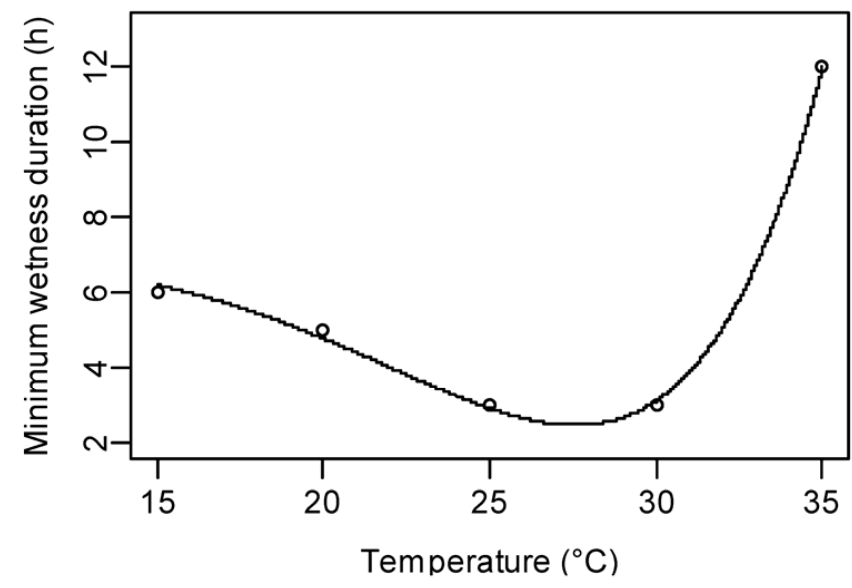

Fig. 5. Minimum wetness duration required for successful infection by Glomerella cingulata conidia, resulting in lesions on the leaves of cv. Gala (Malus domestica), at different temperatures. The leaves were grown on detached shoots, which were water cultured and inoculated with a conidial suspension containing $10^{4}$ Glomerella cingulata conidia per ml; the wetness was maintained for different durations. The symbols represent the mean of the six replications, and the solid line represents the curve of the fitted model (Eq. 3).

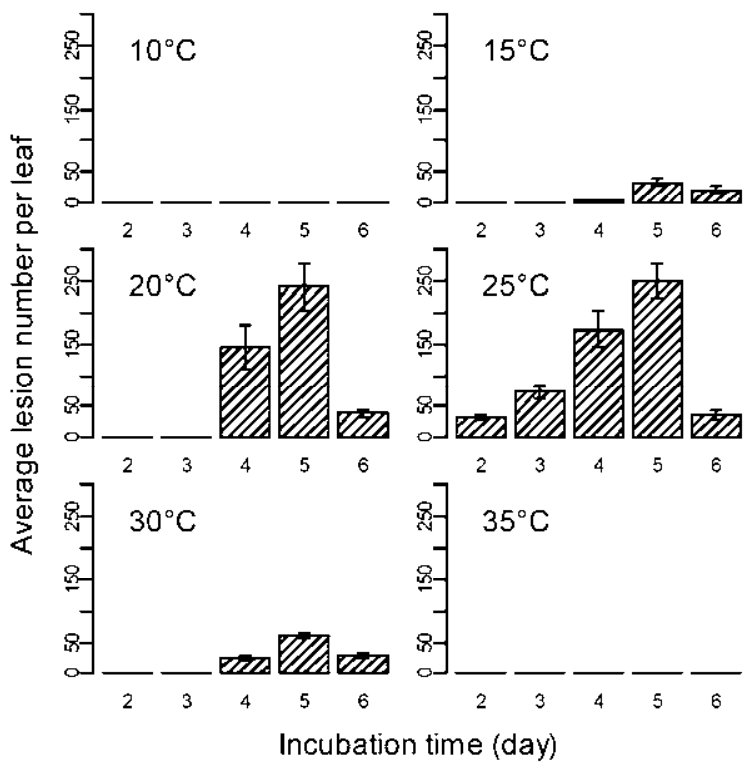

Fig. 6. Average number of Glomerella leaf spots developed on each leaf of cv. Gala (Malus $\times$ domestica) and its corresponding standard error after incubation for different periods of time at six temperatures. The leaves were grown on detached shoots, which were water cultured and inoculated with a conidial suspension containing $10^{4} \mathrm{Glomerella} \mathrm{cingulata} \mathrm{conidia} \mathrm{per} \mathrm{ml}$; the wetness was maintained for $24 \mathrm{~h}$ at $25^{\circ} \mathrm{C}$, and the leaves were then incubated at different temperatures. The bars represent the average number of lesions per leaf from the three replications; six leaves were inoculated for each replication, and the error bars show the standard errors. gests that GLS is very difficult to control after pathogen infection. Because the incubation period is very short, the grower would not have adequate time to apply the fungicide after a long period of rain, during which a large number of conidia can be activated. However, GLS could be primarily controlled by the application of fungicides or the eradication of the pathogens in the early epidemic stages, especially during the primary infection stages. A forecasting system to predict the infection periods and quantity in the early epidemic stages, especially the primary infection stages, would be helpful in controlling this disease. The present study provides the data and models needed to develop such a system.

\section{Acknowledgments}

This research was funded by the National Key Basic Research Program of China (2012CB126302), the China Agriculture Research System (CARS-28) and the Taishan Scholar Construction Project of Shandong Province. We thank Prof. Yong Luo (University of California, Kearney Agricultural Center, USA) for his proposal and assistance in revising the manuscript. We also thank Cui-cui Wang, Chao Li and Daojing Yong for their assistance with the experiments.

\section{Literature Cited}

1. Arauz, L. F., Neufeld, K. N., Lloyd, A. L., and Ojiambo, P. S. 2010. Quantitative models for germination and infection of Pseudoperonospora cubensis in response to temperature and duration of leaf wetness. Phytopathology 100:959-967.

2. Dong, J. H., Luo, L., Wang, C. X., Leng, W. F., Li, G. F., and Li, B. H 2009. Isolating strongly parasitic fungi by single - spore isolation aided with capillary stiletto. Chinese Agric. Sci. Bull. 25:210-212.

3. Dong, X. L., Li, B. H., Zhang, Z. F., Li, B. D., and Xu, X. M. 2006. Effect of environmental conditions on germination and survival of teliospores and basidiospores of the pear rust fungus (Gymnosporangium asiaticum). Eur. J. Plant Pathol. 115:341-350.

4. Furuya, H., Takanashi, H., Fuji, S.-I., Nagai, Y., and Naito, H. 2009. Modeling infection of spring onion by Puccinia allii in response to temperature and leaf wetness. Phytopathology 99:951-956.

5. Gadoury, D. M., and MacHardy, W. E. 1986. Forecasting ascospore dose of Venturia inaequalis in commercial apple orchards. Phytopathology 76:112118.

6. Gadoury, D. M., Stensvand, A., and Seem, R. C. 1998. Influence of light, relative humidity, and maturity of populations on discharge of ascospores of Venturia inaequalis. Phytopathology 88:902-909.

7. González, E., and Sutton, T. B. 1999. First report of glomerella leaf spot (Glomerella cingulata) of apple in the United States. Plant Dis. 83:1074.

8. González, E., and Sutton, T. B. 2004. Population diversity within isolates of Colletotrichum spp. causing Glomerella leaf spot and bitter rot of apples in three orchards in North Carolina. Plant Dis. 88:1335-1340.

9. González, E., Sutton, T. B., and Correll, J. C. 2006. Clarification of the etiology of Glomerella leaf spot and bitter rot of apple caused by Colletotrichum spp. based on morphology and genetic, molecular, and pathogenicity tests. Phytopathology 96:982-992.

10. Harris, R. F., Gardner, W. R., Adebayo, A. A., and Sommers, L. E. 1970 Agar dish isopiestic equilibration method for controlling the water potential of solid substrates. Appl. Microbiol. 19:536-537.

11. Hartman, J. R., Parisi, L., and Bautrais, P. 1999. Effect of leaf wetness duration, temperature, and conidial inoculum dose on apple scab infections. Plant Dis. 83:531-534.

12. Hirst, J. M., and Stedman, O. J. 1962. The epidemiology of apple scab (Venturia inaequalis (Cke.) Wint.). Ann. Appl. Biol. 50:525-550.

13. Jones, A. L., Lillevik, S. L., Fisher, P. D., and Stebbins, T. C. 1980. A microcomputer-based instrument to predict primary apple scab infection periods. Plant Dis. 64:69-72.

14. Keitt, G. W. 1927. Studies of apple scab and cherry leaf spot infection under controlled conditions. Phytopathology 17:45.

15. Keitt, G. W., and Jones, L. K. 1926. Studies of the epidemiology and control of apple scab. Wis. Agric. Exp. Sta. Bull. 73.

16. Lang, A. R. G. 1967. Osmotic coefficients and water potentials of sodium chloride solutions from 0 to $40^{\circ} \mathrm{C}$. Aus. J. Chem. 20:2017-2023.

17. Leite Junior, R. P., Tsuneta, M., and Kishino, A. Y. 1988. Ocorrencia de mancha foliar de Glomerella em macieira no estado do Parana. Informe da Pesquisa-Fundacao Instituto Agronomico do Parana.

18. Li, B. H., Zhao, H. H., Li, B. D., and Xu, X. M. 2003. Effects of temperature, relative humidity and duration of wetness period on germination and infection by conidia of the pear scab pathogen (Venturia nashicola). Plant Pathol. 52:546-552.

19. Li, B. H., Xu, X. M., Li, J. T., and Li, B. D. 2005. Effects of temperature and continuous and interrupted wetness on the infection of pear leaves by conidia of Venturia nashicola. Plant Pathol. 54:357-363.

20. Li, B. H., Yang, J. R., Dong, X. L., Li, B. D., and Xu, X. M. 2007. A dynamic model forecasting infection of pear leaves by conidia of Venturia nashicola and its evaluation in unsprayed orchards. Eur. J. Plant Pathol. 118:227-238. 
21. Luciano, U. C., Carlos, A. F., Rosa, M. V. S., and José, M. C. F. 2002. Epidemiology of apple leaf spot. Sociedade Brasileira de Fitopatologia 27.

22. Navi, S. S., Bandyopadhyay, R., Reddy, R. K., Thakur, R. P., and Yang, X. B. 2005. Effects of wetness duration and grain development stages on sorghum grain mold infection. Plant Dis. 89:872-878.

23. Neufeld, K. N., and Ojiambo, P. S. 2011. Interactive effects of temperature and leaf wetness duration on sporangia germination and infection of cucurbit hosts by Pseudoperonospora cubensis. Plant Dis. 96:345-353.

24. Mills, W. D. 1944. Efficient use of sulfur dusts and sprays during rain to control apple scab. Cornell Ext. Bull. 630.

25. Pfender, W. F. 2003. Prediction of stem rust infection favorability, by means of degree-hour wetness duration, for perennial ryegrass seed crops. Phytopathology 93:467-477.

26. Stensvand, A., Gadoury, D. M., Amundsen, T., Semb, L., and Seem, R. C.
1997. Ascospore release and infection of apple leaves by conidia and ascospores of Venturia inaequalis at low temperatures. Phytopathology 87:1046 1053.

27. Sutton, T. B., and Sanhueza, R. M. 1998. Necrotic leaf blotch of Golden Delicious - Glomerella leaf spot: a resolution of common names. Plant Dis. 82:267-268.

28. Velho, A. C., Stadnik, M. J., Casanova, L., Mondino, P., and Alaniz, S. 2013. First report of Colletotrichum karstii causing Glomerella leaf spot on apple in Santa Catarina State, Brazil. Plant Dis. 98:157.

29. Wang, C. X., Zhang, Z. F., Li, B. H., Wang, H. Y., and Dong, X. L. 2012 First report of Glomerella leaf spot of apple caused by Glomerella cingulata in China. Plant Dis. 96:912.

30. Xu, X. M., Butt, D. J., and Van Santen, G. 1995. A dynamic model simulating infection of apple leaves by Venturia inaequalis. Plant Pathol. 44:865-876. 